\title{
The Positive Influence of Music on the Human Brain
}

\author{
Shiqi Zhang \\ Ashley Hall, Charleston, SC, USA \\ Email: shiqiz1020@gmail.com
}

How to cite this paper: Zhang, S.Q. (2020) The Positive Influence of Music on the Human Brain. Journal of Behavioral and Brain Science, 10, 95-104.

https://doi.org/10.4236/jbbs.2020.101005

Received: September 4, 2019

Accepted: January 19, 2020

Published: January 22, 2020

Copyright (C) 2020 by author(s) and Scientific Research Publishing Inc. This work is licensed under the Creative Commons Attribution-NonCommercial International License (CC BY-NC 4.0). http://creativecommons.org/licenses/by-nc/4.0/

\begin{abstract}
In the past decade, with the rapid development of cognitive neuroscience and brain function detection technology, the relationship between music and brain has increasingly attracted the attention of neuroscientists. More and more research shows that the influence of music on people is not only emotional; it has a positive effect on brain development and cognitive development. Different states of the brain understand music in different ways, stimulating specific areas of the left and right hemispheres of the brain to evoke specific "music memories", causing corresponding physiological changes. Music activities must be based on brain mechanisms and neural mechanisms to complete, and the most basic way of human brain and nervous system activity is communication and signal transmission between cells. In this paper, we explored the influence of music on the brain. We compared the differences in cognition and memory within a group of students with various academic performances. Through the test of color memory, the length of response time is used as a cognitive ability scale. The results showed that the experimental group performed better, confirming that listening to music can have certain positive effect on cognitive ability, specifically, improving memory. Listening to music could enhance the performance and reduce errors in the questions that the color of the word matched.
\end{abstract}

\section{Keywords}

Music, Brain Plasticity, Music Therapy, Cognition and Memory

\section{Introduction}

With the rapid development of cognitive neuroscience and neuroimaging technology, there are more and more researches focused on exploring the relationship between music and its effects on the brain. Since music is fundamentally 
transmitted in the form of sound waves, its interaction with the brain waves has always been the center of many research fields. Research shows that the influence of music on people is not only emotional; it has a positive effect on brain development and cognitive development. Different states of the brain understand music in different ways, stimulating specific areas of the brain, causing corresponding physiological effects. As a result, many researchers see music as a potential therapeutic tool than a mere entertainment, for example, the potential effect of music therapy on Alzheimer's Disease, anxiety, and people with concentration deficiency. With more understanding of this research concentration, more therapeutic options could benefit a broader patient community by providing a higher living quality.

Previous research shows that music can stimulate the areas relating to motor, language, and cognitive functions simultaneously, and effectively improve patients' cognitive and working memory. There's also evidence showing that music training is closely connected to the stimulation of neurons and executive function of the prefrontal cortex. As a result, we seek to find out whether music training could effectively improve the participants' memory function, subsequently improving their learning abilities. We will also explore whether classical music could effectively improve the participants' concentration and learning efficiency. In this study, we performed two sets of experiment to test the connection between music and memory function.

\section{Music and Memory of Brain}

\subsection{Memory}

Generally speaking, the processing of forming a memory involves encoding, storing, retaining, and subsequently recalling information and past experiences. Dating back to 1904, a German evolutionary biologist Richard Semon put forward a theory, suggesting that Mneme is a fundamental organic plasticity that allows the preservation of experience; it is Mneme "which in the organic world links the past and present in a living bond" [1] [2]. He proposed the idea of engram, which refers to the change in the nervous system, or the "memory trace" that preserves the effects of experience. He posited that a memory would leave a physical trace in the brain; and the brain, when stimulated, would replay the memory. Semon's theory about memory inspired many scientists, and it is greatly reflected on the modern theories of memory. In 2012, by employing optogenetic technology, Susumu Tonegawa's lab at MIT first showed that an engram was real [3]. The incident of a 27-year-old American Henry Molaison had his hippocampi removed as a means to cure his seizures but lost his ability to make new memories led to the discovery that hippocampus is required to attain episodic memories. However, these detailed memories are not stored in the hippocampus, instead, are transferred to the brain cortex. In 2017, Tonewaga's lab has revealed the details of how engrams are made in the hippocampus and then uploaded for storage in the brain cortex [1]. Semon proposed his idea of 
engrams decades before researchers understood neural signals are sent by electronic impulses. Since then, researches has decoded much of the electrical signaling, and shown how learning and memory correspond to the strengthening of connections between individual neurons.

\subsection{The Relationship between Memory Differences and Music Training}

Although most studies that examined associations between music training and cognitive abilities had correlational designs, the prevailing bias is that music training causes improvements in cognition [4] [5]. In order to explore whether the differences in individual memory and personality are related to the acceptance of music, we designed the following experiments.

Participants were 8 students selected from an international high school in China. They were adolescents at a stage of rapid mental development through rigorous academic trainings. Participants were divided into four categories (Good, Fair, Limited, and Weak) according to their school academic performance differences. Through the test of color memory, the length of response time is used as a cognitive ability scale. Before the test, as a control group, we analyzed the cognitive ability and academic differences of the four groups of students; then let them accept the same music training, and once again measured the correlation between cognitive ability and academic ability. The correlation results and analysis were given as followings (Figure 1 and Figure 2).

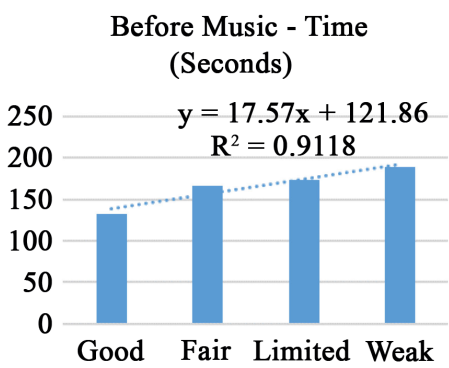

(a)

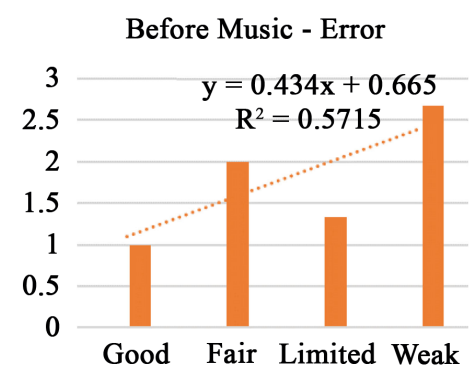

(b)

Figure 1. Cognitive analysis before accepting music. (a) Analysis of reaction time before accepting music; (b) Analysis of errors made before accepting music.

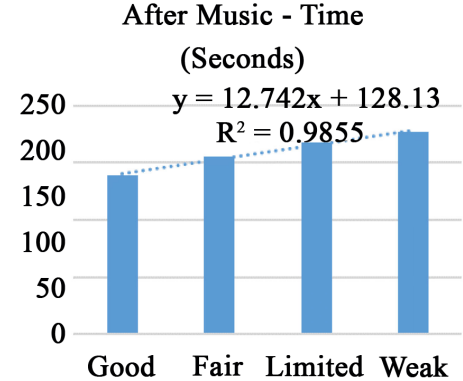

(a)

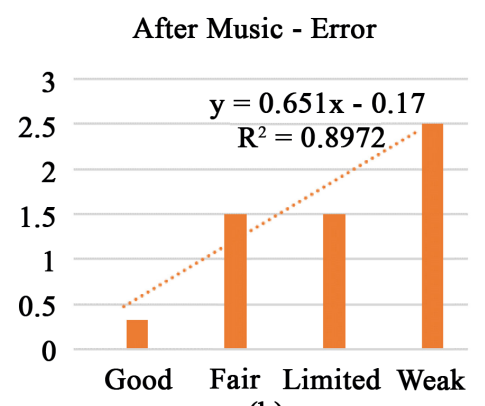

(b)

Figure 2. Cognitive analysis after accepting music. (a) Analysis of reaction time after accepting music; (b) Analysis of errors made after accepting music. 
Both of the trials before and after students listening to music show a strong, direct and positive relationship between the mean time of response and the academic performances of the participants $\left(r^{2}=0.9118, r^{2}=0.9855\right)$. Students in the Good category has the shortest response time compare to other categories. The worse the academic performance, generally the more time the participants spend answering the questions. Similarly, both trials of before and after students listening to music show a direct and positive relationship between the mean errors and the academic performances of the participants $\left(r^{2}=0.5715, r^{2}=0.8972\right)$. Students with better academic performance would make fewer errors, and students with worse academic performances would make relatively more errors. Therefore, there is a positive correlation between academic achievement and students' average reaction time and average error.

To figure out whether music has influences on matched response time and unmatched response time, paired t-tests are performed at $\alpha=0.05$ significance level. The null hypothesis is $\mu_{\mathrm{dmatched}}=0$, and the alternative hypothesis is $\mu_{\mathrm{dmatched}}>0$, where $\mu_{\mathrm{dmatched}}$ is the difference in the mean of the matched median response time before and after listening to music. A paired t-test is used, where $t$ $=\mathrm{x}_{\text {dmatche }} \mathrm{d} /\left(\mathrm{S}_{\text {dmatched }}\right), \mathrm{x}_{\text {dmatched }}=10.88, \mathrm{~S}_{\text {dmatched }}=79.36, \mathrm{n}=8$. The resulting $\mathrm{t}$ value is 0.39 with degrees of freedom of 7 . The $p$-value is 0.35 . Since the p-value is bigger than the significant level ( $\alpha=0.05)$, the result failed to reject the null hypothesis, thus there is no convincing evidence that listening to music could enhance the performance and reduce in errors in the questions that the color of the word matched.

In addition to the matched questions, a paired t-test is performed at $\alpha=0.05$ significance level to determine the significance of listening to music on unmatched question response. The null hypothesis is $\mu_{\text {dunmatched }}=0$, and the alternative hypothesis is $\mu_{\text {dunmatched }}>0$, where $\mu_{\text {dunmatched }}$ is the difference in the mean of the unmatched median response time before and after listening to music. A paired $\mathrm{t}$-test is used, where $\mathrm{t}=\mathrm{x}_{\text {dunmatched }} /\left(\mathrm{S}_{\text {dunmatched }}\right), \mathrm{x}_{\text {dunmatched }}=-36.38, \mathrm{~S}_{\text {dunmatched }}$ $=83.32, \mathrm{n}=8$. The resulting $\mathrm{t}$ value is -1.23 with degrees of freedom of 7 . The $\mathrm{p}$-value is 0.87 . Since the $\mathrm{p}$-value is bigger than the significant level $(\alpha=0.05)$, the result failed to reject the null hypothesis, thus there is no convincing evidence that listening to music could enhance the performance and reduce errors in the questions that the color of the word did not match.

\subsection{Enhance Memory}

As early as the 1960s, Bulgarian Lozanov created the "implicit learning method". He believed that soothing and beautiful classical music can help ease emotional tension, improve concentration, and learn more efficiently [6]. Some scholars believe that musical stimuli generate additional information that interferes with attention, affecting people's memory efficiency [7]. In the past ten years, scientists have extensively explored the relationship between music and memory.

For the molecular biological basis of music affecting memory, researchers believe that music stimulation can change the secretion of some neurotransmitters 
and peptide hormones, thereby enhancing people's memory. Recent studies have found that the secretion of vasopressin AVP $(4-8)$ is significantly increased when the music is felt. It can significantly activate the protein kinase MAPK, which significantly increases the transcription level of the "immediate early gene" c-fos, while c-fos It has a crucial influence on synaptic differentiation and learning and memory [4]. Wang Zengxian et al. (2004) found that music enhances neuronal NMDA receptors and mRNA expression of NMDA receptors [7]; NMDA is one of the most critical proteins for long-term effect (LTP) induction, in the hippocampal neural pathway, NMDA receptors play an important role in the triggering of LTP [8].

\section{Music and Brain Plasticity}

\subsection{Brain Plasticity}

Music, as an important form of artistic expression, has long been a part of art research. In recent years, with the rapid development of brain imaging technologies such as event-related potential (ERP), electroencephalography (EEG), magnetoencephalography (MEG), and functional magnetic resonance imaging (fMRI), music has gradually been incorporated into cognitive neuroscience. Brain plasticity means that the brain can be modified by the environment and experience, and has the ability to shape the structure and function of the brain under the influence of the external environment and experience.

Animal experiments have found that music can promote brain development in rats and mice, enhance nerve plasticity, and improve their spatial learning and memory. The auditory cortex NMDA receptor is a vital neural connective pathway in mammalian learning and memory processes, including humans. After listening to Mozart's "Big Piano Sonata", the expression of NMDA subunit NR2B protein in 2 weeks old mice increased significantly, and the spatial memory ability increased accordingly. In addition, the improvement of memory ability depends on the length of music stimulation time and is related to the up-regulation of NMDA receptor expression in hippocampal formation [8]. The University of California, Berkeley, Diamond, and others have performed a series of well-known experiments in white mice. The results showed that the thickness of the gray matter of white rats in the living environment increased, and the proportion of the cortex in the whole brain increased, and each nerve cell increased by $15 \%$. The study also found that white mice living in a rich environment were $25 \%$ more connected than white mice in the normal environment, and they performed better in the test. More importantly, Greenough also found that when the adult mouse responds to a complex environment, the brain also forms new synapses.

Related experiments have also shown that after special training, brain-related cortical representations can change significantly. This shows that the cortical representation area of feeling, movement, language, cognition, etc. is not fixed, but a dynamic structure. Experience or training can reorganize the fine structure of 
the representative area. This empirically dependent structural reorganization can be used to explain why people or animals learn certain intelligence and motor skills [9].

\subsection{The Influence of Music on Brain Plasticity}

As we all know, music is the sound art that shapes the artistic image through sound. Whether it is the listening and feeling of various factors such as pitch, tone, rhythm, harmony and melody, or integrating these elements into a complete piece for performance. The auditory cortex in the individual brain plays an important role in monitoring and recognizing, and thus involves complex brain activities such as sound analysis, auditory memory, and auditory scene analysis [10] [11].

Christo Pantev's research (1998) in Master University shows that musicians are particularly sensitive to piano sounds, mainly because their auditory cortical activity area is significantly enhanced when they hear piano sounds. Those who learn instrumental music before the age of 9 have the largest area of auditory cortex activity, but ordinary people do not have such significant changes [12]. Thomas Elbert (1995) of Konstanz University in Germany reported that the cortical region of the left-handed activity of string players (average age 20 years) is larger than the average person, and the younger the learning instrument is, the more relevant. The area of the cortex is also larger. A comparative study of musicians and non-musicians by Schlaug et al. (1995) found that the left side of the musician's traverse is significantly larger than the right side, and the traverse is the area in the human brain that processes auditory information. Although the left side of the non-musician cross is larger than the right side, the difference is small, but the difference between musicians is twice that of non-musicians. Schlaug also found that musicians have an average cerebellum that is $5 \%$ larger than non-musicians. This shows that finger movement for many years promotes additional nerve growth [13].

The brain is a special structure developed by human beings to adapt to the needs of survival. Its main task is to collect information about the internal and external environment of the body, and to process the information specifically to make decisions and responses that are suitable for the environment and for survival [14]. Music can enhance the interrelationship between EEG signals in each channel and build a network of brain functions, which can significantly improve the activity of the brain.

\section{Clinical Study of Music Therapy}

Music therapy is a treatment method that enhances the physical and mental health of individuals by using music activities as a medium of treatment. "Music Therapy", which combines music, medicine and psychology, is a study of the role of music in human function and how to apply music to treat diseases. From a physiological analysis, music therapy is the result of objective stimuli for cen- 
tral nervous system stimulation. When external or internal factors stimulate the hypothalamic and other subcortical centers that are responsible for emotions, it will cause changes in the activity of the emotional nervous system [9].

Stroke is a persistent cerebral hemisphere or brainstem focal neurological deficit caused by acute cerebrovascular circulatory disorder. The domestic morbidity rate is about $30 \%$ to $50 \%$ [15]. Modern medicine combines the physical and psychological healing of patients. Studies have shown that the use of music therapy in combination with drug therapy has a significant effect on the treatment of senile depression, schizophrenia and preoperative anxiety [16]. Music therapy is divided into active and passive. Passive music therapy is also known as perceptual music therapy; patients mainly listen carefully, wholeheartedly into the music, and feel the beauty of music; and active music therapy is that patients actively participate in music activities, such as singing, using musical instruments. At present, most of the music therapy uses VCD and Walkman, and most of the patients are passively listening. Music therapy for post-stroke depression has been reported more and more in China, especially for the study of national conditions and regional differences, the application of different populations and the efficacy [12] [17] [18] [19].

In the medical field, the results of music therapy in China have been fully affirmed by the academic community. The most widely used neurological disorder in domestic music therapy is the sequela of stroke. The earlier report was Liu Mingjia, the second nursing home of Qingdao Jinan Military Region, Medical Electrotherapy for the Treatment of 60 Cases of Cerebral Thrombosis [12]. Liu Yanping et al. used a combination of susceptibility music therapy and exercise therapy to treat patients with post-stroke limb paralysis. It was found that susceptibility music therapy combined with exercise therapy can improve limb paralysis and reduce muscle tone in stroke patients [3]. Jeong $\mathrm{SH}$ et al. showed for the first time that music listening in the early stages of a stroke could enhance cognitive recovery and prevent negative emotions. Cha, Y et al. (2014) investigate the effect of intensive gait training with rhythmic auditory stimulation on postural control and gait performance in individuals with chronic hemiparetic stroke [16].

Twenty patients with chronic hemiparetic stroke participated in this study. Subjects in the Rhythmic auditory stimulation training group (10 subjects) underwent intensive gait training with rhythmic auditory stimulation for a period of 6 weeks (30 min/day, five days/week), while those in the control group (10 subjects) underwent intensive gait training for the same duration. Two clinical measures, Berg balance scale and stroke specific quality of life scale, and a 2-demensional gait analysis system, were used as outcome measure. To provide rhythmic auditory stimulation during gait training, the MIDI Cuebase musical instrument digital interface program and a KM Player version 3.3 were utilized for this study. The results showed that intensive gait training with rhythmic auditory stimulation resulted in significant improvement in scores on the Berg balance scale, gait velocity, cadence, stride length and double support period in 
affected side, and stroke specific quality of life scale compared with the control group after training.

Music therapy is a planned and purposeful treatment process guided by medical psychology and using music activities as the main body. The specifications of its treatment methods, procedures, and content are still being explored and practiced. Music has a direct impact on the limbic system and brainstem structure through physical and physiological functions. Its melody can invigorate the spirit, stimulate thinking, stimulate normal behavior, improve the emergency response ability of stroke patients, and enable the patient's original living ability to be exerted [19].

\section{Conclusion}

Looking back at the past research work, we strongly felt that the relationship between music and the brain has become a frontier field in the study of brain science and music psychology [9]. Undoubtedly, the influence of music on the human brain can be objectively determined by scientific means. Music training has outstanding effects on human brain development as well as cognitive and memory development. Music therapy can reduce the patient's anxiety level, thereby improving mood and reducing the response to psychological depression. It is widely used in the modern medical field to treat diseases such as stroke depression [20]. In addition, music training also shows significant effect on memory enhancement in a clear molecular level. These studies have further deepened people's understanding of the value of music education, and made music education show more in the broader development of human development and human potential.

\section{The Limitation and Future Work}

In future research, the study should incorporate more participants, and groups of participants should be sampled from different schools. This would ensure to reduce the variability of the estimates made from the data collected in the experiment. Sampling from different schools would allow us to make inferences on a wider population.

\section{Conflicts of Interest}

The author declares no conflicts of interest regarding the publication of this paper.

\section{References}

[1] Semon, R. (1921) The Nmeme. George Allen \& Unwi, London.

[2] Kitamura, T., et al. (2017) Engrams and Circuits Crucial for Systems Consolidation of a Memory. Science, 356, 73-78. https://doi.org/10.1126/science.aam6808

[3] Liu, X., Ramirez, S., Pang, P., Puryear, C., Govindarajan, A., Deisseroth, K. and Tonegawa, S. (2012) Optogenetic Stimulation of a Hippocampal Engram Activates 
Fear Memory Recall. Nature, 484, 381-385. https://doi.org/10.1038/nature11028

[4] Hilliard, R.E. (2005) Music Therapy in Hospice and Palliative Care: A Review of the Empirical Data. Evidence-Based Complementary and Alternative Medicine, 2, 173-178. https://doi.org/10.1093/ecam/neh076

[5] Ueda, T., Suzukamo, Y., Sato, M. and Izumi, S.I. (2013) Effects of Music Therapy on Behavioral and Psychological Symptoms of Dementia: A Systematic Review and Meta-Analysis. Ageing Research Reviews, 12, 628-641. https://doi.org/10.1016/j.arr.2013.02.003

[6] North, A.C., Sheridan, L.P. and Areni, C.S. (2016) Music Congruity Effects on Product Memory, Perception, and Choice. Journal of Retailing, 92, 83-95. https://doi.org/10.1016/j.jretai.2015.06.001

[7] Wang, H., Jiang, J. and Jiang, C. (2015) The Effects of Music Training on Cognitive Abilities. Advances in Psychological Science, 23, 419-429. https://doi.org/10.3724/SP.J.1042.2015.00419

[8] Korsos, G., Horvath, K., Lukacs, A., Vezer, T., Glavits, R., Fodor, K., et al. (2018) Effects of Accelerated Human Music on Learning and Memory Performance of Rats. Applied Animal Behaviour Science, 202, 94-99. https://doi.org/10.1016/j.applanim.2018.01.011

[9] Jentschke, S. and Koesch, S. (2006) Brain, Music, Plasticity and Development. Zeitschrift Fur Erziehungswissenschaft, 9, 51-70. https://doi.org/10.1007/978-3-531-90607-2_5

[10] Koizumi, H. (2008) Ismbe. Dawn of "Brain-Science \& XYZ": XYZ from the Social Sciences, the Humanities and the Arts. 3-5.

[11] Seibert, P.S., Fee, L., Basom, J. and Zimmerman, C. (2000) Music and the Brain: The Impact of Music on an Oboist's Fight for Recovery. Brain Injury, 14, 295-302. https://doi.org/10.1080/026990500120763

[12] Koelsch, S. (2009) A Neuroscientific Perspective on Music Therapy. Annals of the New York Academy of Sciences, 1169, 374-384. https://doi.org/10.1111/j.1749-6632.2009.04592.x

[13] Ferreri, L. and Rodriguez-Fornells, A. (2017) Music-Related Reward Responses Predict Episodic Memory Performance. Experimental Brain Research, 235, 3721-3731. https://doi.org/10.1007/s00221-017-5095-0

[14] Markman, A.B. (2007) A Tribute to Larry Erlbaum. Cognitive Science, 31, 1. https://doi.org/10.1080/03640210709336983

[15] Corrigall, K.A., Schellenberg, E.G. and Misura, N.M. (2013) Music Training, Cognition, and Personality. Frontiers in Psychology, 4, 222. https://doi.org/10.3389/fpsyg.2013.00222

[16] Cha, Y., Kim, Y., Hwang, S. and Chung, Y. (2014) Intensive Gait Training with Rhythmic Auditory Stimulation in Individuals with Chronic Hemiparetic Stroke: A Pilot Randomized Controlled Study. Neurorehabilitation, 35, 681-688. https://doi.org/10.3233/NRE-141182

[17] Erkkila, J., Punkanen, M., Fachner, J., Ala-Ruona, E., Pontio, I., Tervaniemi, M., et al. (2011) Individual Music Therapy for Depression: Randomised Controlled Trial. British Journal of Psychiatry, 199, 132-139. https://doi.org/10.1192/bjp.bp.110.085431

[18] Kemper, K.J. and Danhauer, S.C. (2005) Music as Therapy. Southern Medical Journal, 98, 282-288. https://doi.org/10.1097/01.SMJ.0000154773.11986.39

[19] Sarkamo, T., Tervaniemi, M., Laitinen, S., Forsblom, A., Soinila, S., Mikkonen, M., 
et al. (2008) Music Listening Enhances Cognitive Recovery and Mood after Middle Cerebral Artery Stroke. Brain, 131, 866-876. https://doi.org/10.1093/brain/awn013

[20] Maratos, A.S., Gold, C., Wang, X. and Crawford, M.J. (2008) Music Therapy for Depression. Cochrane Database of Systematic Reviews, No. 1, CD004517. https://doi.org/10.1002/14651858.CD004517.pub2 